\section{Phytocatalytic Utility of Unripe Banana Peel Water as a Novel Matrix for Benzoylation of Amino Containing Functionality}

\section{Abstract}

We herein reports unripe banana peel water as an alternate medium for benzoylation of aromatic amino containing functionality especially aniline, further concluded that same methodology could be used for benzoylation purposes of other aromatic compounds containing similar functionality. Compared to conventional methodology, the catalytic system we reported here is superior in multiple aspects and devoid of using any non-eco-friendly hazardous organic/ inorganic alkaline matrix.

Keywords: Benzoylation; Unripe banana peel water; Phytocatalytic

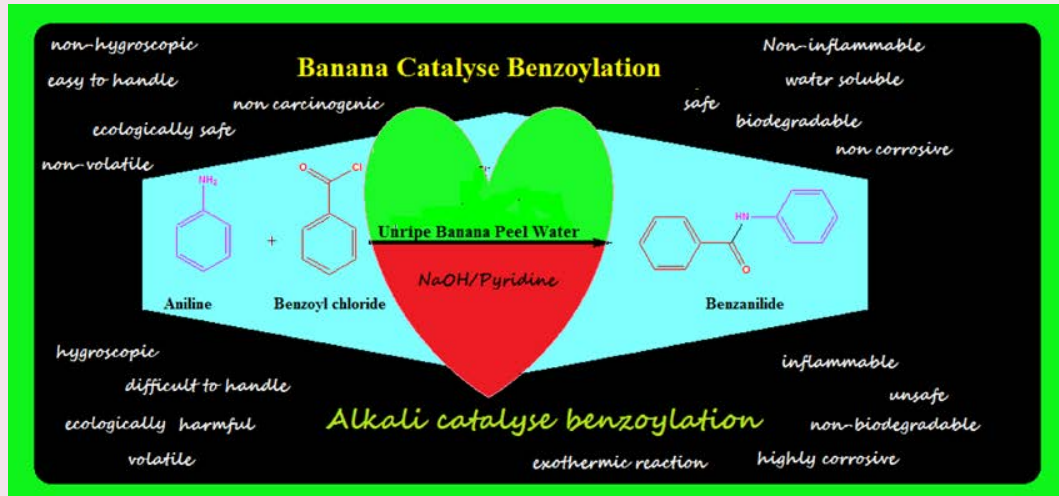

\section{Deepak Chowrasia and} Nisha Sharma

University Institute of Pharmacy, CSJM University, Kanpur-208024, India

Corresponding author: Deepak Chowrasia

” chowrasia.deepak@gmail.com

University Institute of Pharmacy, CSJM University, Kanpur-208024, India.

Tel: +91-9451-019049

Citation: Chowrasia D, Sharma N.

Phytocatalytic Utility of Unripe Banana Peel Water as a Novel Matrix for Benzoylation of Amino Containing Functionality. Arch Chem Res. 2017, 1:2.

\section{Introduction}

It is now a well evident fact that catalyst and solvent affects both the reaction rate as well as outcome of a chemical reaction. On the basis of practical and industrial applicability, numerous techniques were evaluated for substitution/modification of later [1-3] although the same could not be true for former comparatively, owing to its specificity and selectivity towards a particular type of chemical reaction or desired product needed from same along with decisive direct influence on outcomes of a chemical phenomenon (reaction rate, product purity, its yield, and economic value etc.) and its kinetics (Figure 1).

Benzoylation, a phenomenon involves introduction of ArCOfunctionality (Scheme-01) is an effective, economic, and handy technique, not only used to protect and identify amino as well as hydroxyl group present in an aromatic as well as aliphatic organic compounds, but is also equally important in their synthetic

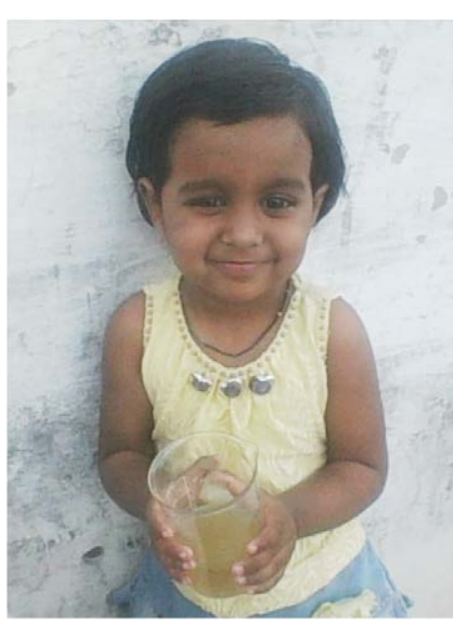

Figure 1 Child holding unripe banana peel water. 
chemical transformation subsequently into amide ( $\left.\mathrm{Ar}^{\prime} \mathrm{CONHAr} / \mathrm{R}\right)$ or ester derivatives ( $\left.\mathrm{Ar}^{\prime} \mathrm{CO}-\mathrm{OAr} / \mathrm{R}\right)$ in the presence of alkaline catalyst (aqueous solution of sodium hydroxide or pyridine) [48 ] and benzoylating agent-benzoyl chloride or their substituted derivatives (Schotten-Baumann reaction) [7,8]. High melting point, resistance towards hydrolysis in aqueous medium, and insolubility of benzoylated derivatives makes the technique of benzoylation advantageously distinguished among acetylation (introduction of RCO-group), thus preferred comparatively $[9,10]$.

\begin{tabular}{lcl} 
& $\mathrm{NaOH}(10 \%)$ & \\
\cline { 2 - 2 } $\mathrm{Ar}-\mathrm{X}+\mathrm{Ar} \mathbf{C}^{\prime} \mathrm{COCl}$ & Ar-Y-COAr' $+\mathrm{HCl}$ \\
$\mathrm{X}-\mathrm{NH}_{2}$ & $\mathrm{Stir} 30-35 \mathrm{~min}$ & Y-NH \\
$\mathrm{X}-\mathrm{OH}$ & $\mathrm{RT}$ & Y-O
\end{tabular}

\section{Scheme-01}

The alkaline catalyst in benzoylation mechanistically provides necessary driving force to shift the reaction towards forward direction by absorbing protons evolved during benzoylation, side by strengthen the attacking power of acid chloride participating in the chemical reaction. Whatsoever the alkaline catalyst deployed to assist the reaction is neither absolutely free from undesirable hazardous effect both on person handling the reaction and environment nor practically cost effective. Nevertheless when same catalyst used for industrial applicability, imposes an extra cost burden on manufacturing processes thus on consumption line. In contrast, the phyto-catalyst system we herein reports is free from aforesaid restrictions and extraordinarily advantageous for inprocess applicability and harmless for ecosystem (Figure 2).

\section{Materials and Methods}

All the reagents and solvents used in this experimentation are acquired from common store University Institute of Pharmacy, CSJM University, Kanpur, India and used as \& their basis without any modification unless or until specified. The unripe bananas used for preparation of water for benzoylation were purchased from Ramadevi Sabzi Mandi, Kanpur, India. Since compound synthesized to evaluate banana peel water for elucidating its feasibility for benzoylation is reported and spectrally characterized hence a comparative study between synthesized and reported compound was done to enumerate its practicability (Table 1 ). The melting point for synthesized compounds was recorded by open capillary method in triplicate and is uncorrected. The progression of reaction was monitored in PET ether:ethylacetate (8:2) as a binary solvent system on a pre-prepared TLC plate.

\section{Experimental}

\section{Preparation of banana water}

The unripe, matured (banana with green peel color), and healthy bananas were selected carefully for making banana peel water. Sufficient communication before selecting banana for experimentation was established with shopkeepers. The unripe banana so obtained were washed thoroughly from distilled water, dried suitably at lower temperature, and carefully peeledoff with knife such that the outer covering of banana could be separated from inner white edible (body) portion. The peels (20 g) were then transferred into a beaker $(500 \mathrm{ml})$ and were cold macerated (with distilled water; $300 \mathrm{ml}$ ) at room temperature for 72-hours. On completion peels were separated from mother liquid (black in color), which is further filtered off carefully to remove any suspended or un-dissolved particle.

\section{Evaluation of benzoylating efficiency of banana peel water}

The efficiency of unripe banana peel water as a medium for synthesizing benzoylated derivatives was evaluated by dissolving or suspending equimolar quantity $(0.01 \mathrm{M})$ of reactant (aniline) and benzoyl chloride in banana peel water (15 ml; Figure 3). The content was shaken for the sufficient period of time (under fuming hood), yielding crude product, was further washed thoroughly from cold water and finally recrystallized from ethanol.

\section{Results and Discussion}

The phytocatalytic technique for benzoylation we herein develop and reports is unique and advantageous over traditional methodology (Table 2) in terms of cost effectiveness, eco-

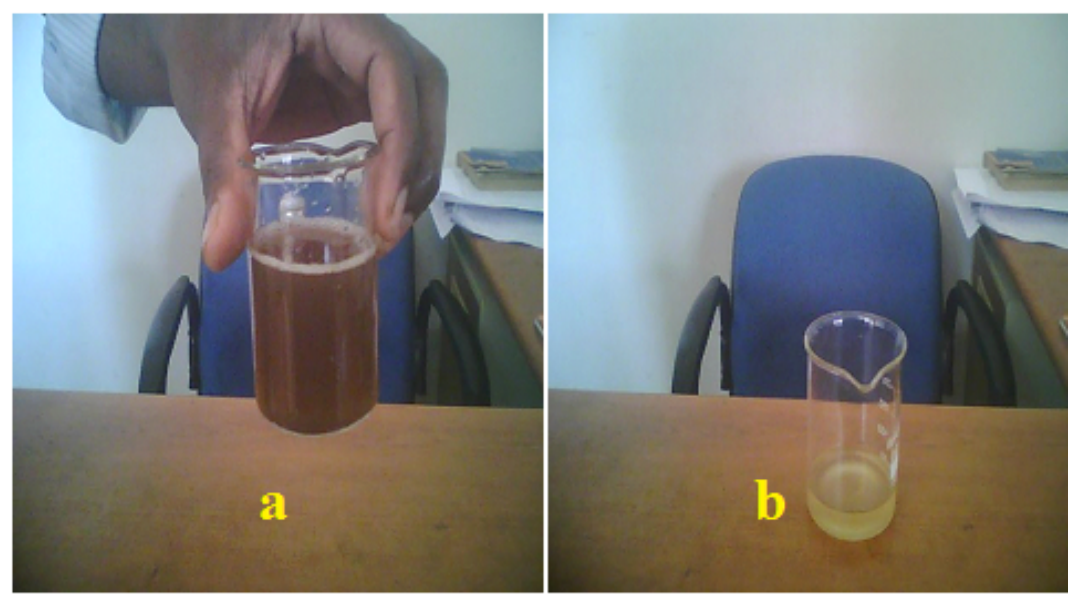

Figure 2 Unripe banana peel water- unfiltered (a) \& filtered (b). 
Table 1 Comparative physiochemical characteristic of benzoylated derivative synthesised in unripe banana peel water with that of standard.

\begin{tabular}{|c|c|c|c|c|}
\hline $\begin{array}{l}\text { Physiochemical/qualitative } \\
\text { parameters }\end{array}$ & $\begin{array}{l}\text { Reference benzanilide } \\
\text { (Commercially available) }\end{array}$ & $\begin{array}{l}\text { Benzanilide Synthesize } \\
\text { in traditional catalyst }\end{array}$ & $\begin{array}{l}\text { Benzanilide Synthesize in } \\
\text { unripe banana peel water }\end{array}$ & Inferences \\
\hline $\begin{array}{l}\text { Physical appearance } \\
\text { Before recrystalization } \\
\text { After recrystalization }\end{array}$ & $\begin{array}{l}\text { Yellowish white } \\
\text { White/colorless crystal }\end{array}$ & $\begin{array}{l}\text { Yellowish white } \\
\text { White/colorless crystal }\end{array}$ & $\begin{array}{l}\text { Yellowish white } \\
\text { White/colorless crystal }\end{array}$ & $\begin{array}{l}\text { Synthesized product having } \\
\text { similar appearance as that of } \\
\text { reference }\end{array}$ \\
\hline $\begin{array}{l}\text { Solubility } \\
\text { Water (cold) } \\
\text { Water (hot) } \\
\text { Methanol } \\
\text { Ethanol } \\
\text { Chloroform }\end{array}$ & $\begin{array}{c}- \\
- \\
+ \\
++ \\
+++\end{array}$ & $\begin{array}{c}- \\
- \\
+ \\
++ \\
+++\end{array}$ & $\begin{array}{c}- \\
- \\
+ \\
++ \\
+++\end{array}$ & $\begin{array}{c}\text { Difference in Solubility of } \\
\text { reactants \& products in nonpolar } \\
\text { organic solvent indicates addition } \\
\text { of aromatic ring (lipophillic } \\
\text { character). }\end{array}$ \\
\hline Melting point $\left({ }^{\circ} \mathrm{C}\right)$ & 163 & 162 & 166 & $\begin{array}{l}\text { Within the range Melting point } \\
\text { indicates synthesis of benzanilide }\end{array}$ \\
\hline $\begin{array}{l}\text { Qualitative detection of } \\
\text { residual benzoyl chloride in } \\
\text { product } \\
\text {-Silver nitrate test }\end{array}$ & Negative & Negative & Negative & $\begin{array}{l}\text { Chlorine absent, benzoyl chloride } \\
\text { exhausted; benzoylation done }\end{array}$ \\
\hline $\begin{array}{l}\text { Qualitative detection of sulphur } \\
\text { in product } \\
\text {-Sodium nitroprusside test }\end{array}$ & Negative & Negative & Negative & Sulphur absent \\
\hline $\begin{array}{l}\text { Qualitative detection of free } \\
\text { phenolic group in product } \\
\text {-Ferric chloride test }\end{array}$ & Negative & Negative & Negative & $\begin{array}{l}\text { Phenolic group absent/ test not } \\
\text { applicable }\end{array}$ \\
\hline $\begin{array}{l}\text { Qualitative detection of free } \\
\text {-NH group in product } \\
\text {-Dye test }\end{array}$ & Negative & Negative & Negative & $\begin{array}{l}\text { Free }-\mathrm{NH} \text { group absent; } \\
\text { benzoylation done }\end{array}$ \\
\hline
\end{tabular}

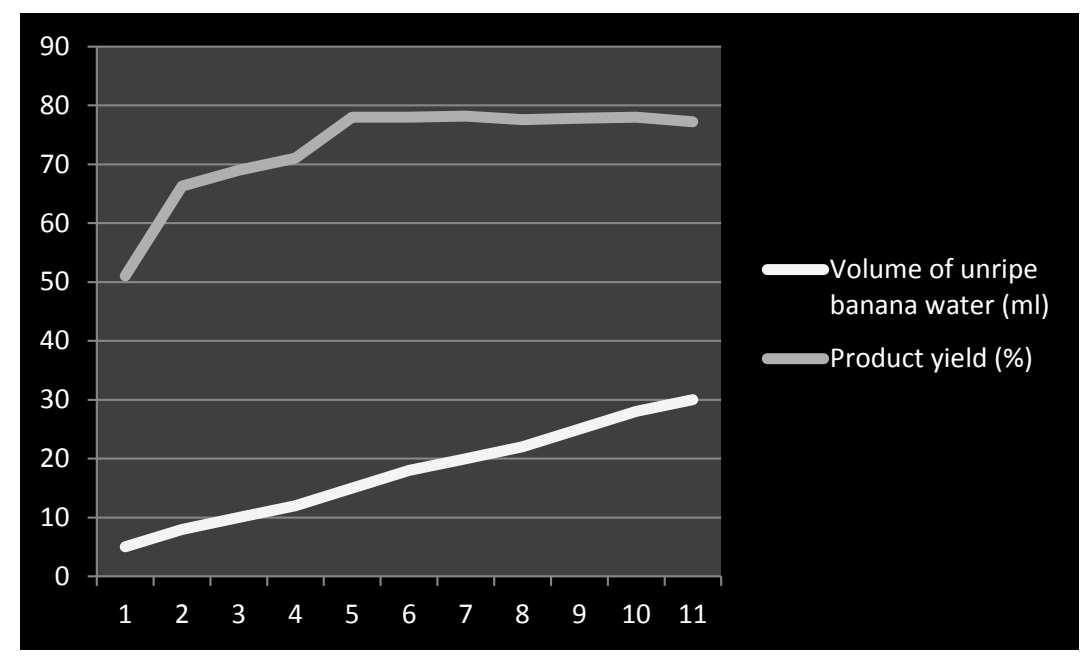

Figure 3 Optimized quantity of unripe banana peel water and it effect on product yield at constant concentration of reactants $(0.1 \mathrm{M})$.

compatibility, and is entirely free from using any harmful alkaline catalytic medium to assist the reaction. The unripe banana peel water was successfully evaluated to elucidate its synthetic harmony for benzoylating monocarbocyclic aromatic ring system containing amino functionality (Figure 4). We further claims (on the basis of our experimentation result) that the technique we herein reported can equally be applied for yielding benzoylated derivatives of polycarbocyclic aromatic as well as aliphatic compounds containing hydroxyl and amino groups including protecting N-terminal ends of amino acids for peptide synthesis however the same was reserved as a future workup plan of ours. The benzoylated derivative of aniline by this methodology was yielded practically in excellent yield, and is comparable with the product obtained by traditional chemical pathway. Furthermore, the quantity of unripe banana peel water used for benzoylation against particular quantity of reactants were optimized, was found that even a quantity less than $15 \mathrm{ml}$ is appropriate (Figure 3) for normal yield of benzoylated product however any quantity 
Table 2 Catalyst used for industrial applicability.

\begin{tabular}{|c|c|c|}
\hline Reaction conditions & Conventional benzoylating pathway & Phytocatalytic benzoylating pathway \\
\hline Host reactant & Aniline $(0.1 \mathrm{M})$ & Aniline $(0.1 \mathrm{M})$ \\
\hline Benzoylating agent & Benzoyl chloride $(0.1 \mathrm{M})$ & Benzoyl chloride $(0.1 \mathrm{M})$ \\
\hline Catalyst used & Sodium hydroxide (10\%) & Unripe banana peel water \\
\hline Catalyst preparation & Tedious & Easy \\
\hline Catalyst handling & Need special care & Easy \\
\hline Catalyst effect on human & Harmful & None \\
\hline Catalyst effect on environment & Harmful & None \\
\hline Catalyst biodegradability & Non-biodegradable & Biodegradable \\
\hline Catalyst cost & Costlier & Cheap; even none \\
\hline Catalyst quantity used & 15 ml & 15 ml* (see Figure 4) \\
\hline Reaction temperature $\left({ }^{\circ} \mathrm{C}\right)$ & RT & RT \\
\hline Reaction time & 20 -minutes & 12 -minutes \\
\hline Product yield $(\%)$ & 85 & 78 \\
\hline Recrystallization requirement & Yes & Yes \\
\hline Recrystallization solvent & Ethanol & Ethanol \\
\hline
\end{tabular}

*quantity even less is effective.

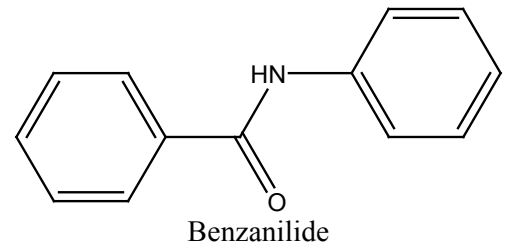

Figure 4 Benzoylated derivative of aniline prepared in unripe banana peel water.

beyond a particular amount $(10-8 \mathrm{ml})$ affects the yield of product as well as its purity. Likewise volume of unripe banana peel water greater than $15 \mathrm{ml}$ is equally effective to yield product although a volume next to $20 \mathrm{ml}$ is wastage to medium.

\section{Conclusion}

Though overall yield of benzoylated derivatives we found in unripe banana peel water is not comparable with traditional alkaline solvents nevertheless its practicability in terms of cost effectiveness and eco-compatible is unquestionable. Furthermore the unripe banana peel water alone or used in combination with other alkaline solvent the net cost for industrial production of benzoylated derivatives could efficiently be minimized. Since the unripe banana peel water is comparatively less/no basic than conventional alkaline solvents thus the same could be used for benzoylation of amino acid without causing their racemization. However as per our prediction, the unripe peel banana peel water could be used efficiently for yielding benzoylated derivative of aniline. 


\section{References}

1 Earle MJ, Seddon KR (2000) lonic liquids green solvents for the future. Pure Appl Chem 72:1391-1398.

2 Abou-Shedhada S, Clark JH, Paggiola G, Sherwood J (2016) Tunable solvents: Shades of green. chem Eng Proc 99:96-98.

3 Chowrasia D, Sharma N (2016) Solvent Substitution Evaluation of Limestone Water as a Medium for Benzoylation. Arch Chem Res 1.

4 Greene TW (1981) Protective groups in organic synthesis. Wiley NY, USA, pp: 261-263.

5 Reese CB (1973) Protective groups in organic chemistry Plenum press London, UK, pp:52-53.
6 Ando W, Tsumaki H (1983) A facile preparation of aliphatic hydroxamic acid from N,N,O-tris(trimethylsilyl)hydroxylamine and acid chloride. Synthetic communications 13:1053-1056.

7 Taylor EC, Mclay GW, McKillop A (1968) Thallium in organic synthesis. II. Acylation, Aroylation, and tosylation, of phenol and carboxylic acid. Journal of American chemical Society 90:2422-2423.

8 Illi VO (1979) Phase transfer catalyzed acylation. Tetrahedron Letters 20:2431-2432.

9 Vogel Al (1956) Practical organic chemistry, Longman group limited London, pp: 582-583.

10 Mann FG, Saunders BS (1978) Practical organic chemistry, Longman group limited London, pp: 243-244. 